\title{
Interrogatorio y contrainterrogatorio: una mirada académica - teoría y práctica
}

\author{
Interrogation and cross-examination: \\ a theoretical and practical approach
}

María N. López Betancur`; John F. Gómez Rendón²

\section{Resumen}

La entrada en vigencia del nuevo Sistema Penal Acusatorio en Colombia (Ley 906 de 2004) representa una transformación significativa del paradigma para la justicia penal particularmente. Este artículo aborda las cuestiones más álgidas de esa transformación e intenta señalar los retos que se les plantean a los operadores jurídicos y a todo profesional del derecho que se enfrente al nuevo sistema, especialmente en lo referente a los procesos de interrogatorio y contrainterrogatorio que son capitales en el nuevo sistema.

Palabras clave: sistema acusatorio, confrontación, prueba testimonial, impugnación, interrogatorio, contrainterrogatorio, estrategias.

\section{Abstract}

The adoption in Colombia of the prosecutorial system of criminal procedure (Law 906, 2004) represents a significant paradigmatic transformation, particularly for the criminal justice system. This article addresses the most crucial issues involved in that transformation and seeks to highlight the challenges faced by legal practitioners and professionals dealing with the new system, especially with regard to the process of interrogation and cross-examination, which is paramount in the new system.

Keywords: prosecutorial system, confrontation, testimonial evidence, contestation, interrogation, cross-examination, strategies. 


\section{Introducción}

Si quieres ser sabio, aprende a interrogar razonablemente, a escuchar con atención, a responder serenamente y a callar cuando no tengas nada que decir.

Johann Caspar Lavater

Con la entrada en vigencia del Sistema Penal Acusatorio (Ley 906 de 2004), para todos los operadores jurídicos es de abultado conocimiento el gran cambio de paradigma y modelo a seguir en lo atinente a lo que de administración de justicia de índole penal se trata, es notorio y de palmaria visualización la gran trascendencia e importancia de la aplicación de la Constitución y los principios rectores en la Sistemática Procesal Penal Acusatoria. Por fortuna hoy por hoy se han superado tantos velos y cortapisas concernientes a una verdadera aplicación de los derechos y garantías que surgen para los vinculados dentro de un proceso penal; esas cortinas o telas que cubrían el desarrollo efectivo de las diligencias judiciales en las cuales imperaban los juicios e investigaciones privadas, oscuras y escritas, que por mucho tiempo rigieron los destinos de los implicados en el proceso.

A partir de los siguientes renglones se hará un análisis del interrogatorio y del contrainterrogatorio desde lo teórico tratando de acercarlo un poco a lo práctico, claro está, sin pretender traer algo nuevo en el tema, sino más bien extender y explicar lo ya expuesto por personas que poseen gran prestigio y crédito por su calidad y competencia en la materia, aportando y contribuyendo (pero desde una posición muy humilde y con un discurso y estilo académico de estudiante universitario) al estudio del derecho penal.
Interrogatorio y

contrainterrogatorio: una mirada

académica - teoría y práctica

A partir del año 1991, en nuestro país el derecho penal está constitucionalizado en razón a que la Ley tiene que obedecer a la Constitución. Por ello es oportuno tomar las palabras de Jaramillo Díaz quien señala que:

La Constitución Política de 1991, ideológicamente liberal, impone entonces la tendencia acusatoria. Su soporte político está dado en los elementos Estado constitucional de derecho, Estado social, régimen republicano y régimen democrático, previstos en el artículo 1, el proceso debido en el artículo 29, la función jurisdiccional constitucional en el artículo 116, el mensaje de eficacia procesal diseñado en el 228 y el derecho fundamental de acceso al Estado jurisdicción, entre otros (2008, p.15).

Es decir, «la sistemática procesal penal mixta acusatoria está sustentada y ordenada en la Constitución Política de 1991 para la actuación, y no solamente para el proceso. De lo contrario, habría sido sin duda un avance a medias» (Jaramillo Díaz, 2008, p. 146).

Queda entendido que Colombia es un Estado social de derecho, el cual trae inmersa una serie de derechos y garantías a favor de todos los asociados, y con el ajuste hecho a través del acto legislativo 03 de 2002 (modificatorio de los artículos 116, 250 y 251 de la Constitución) se implementó la Sistemática Acusatoria en nuestro país (Avella Franco, 2007, p. 17), trayendo consigo garantías cardinales en lo tratante a la aplicación de la misma. Una de esas razonables y sensatas adquisiciones es la confrontación que constituye sin lugar a dudas un componente del debido proceso, este derecho se ha entendido como «el derecho a 
interrogar o hacer interrogar a los testigos de cargo» (Bedoya Sierra, 2013, p. 35).

Precisamente la anterior definición nos permite no perder de vista la oralidad, ${ }^{7}$ habida cuenta de que los fallos y disposiciones judiciales habrán de fundarse en los medios de prueba aportados de forma oral, y es lógico que se interrogue y contrainterrogue de forma oral y en este sentido, como lo diría Ferrajoli (citando a Chiovenda y Calamandrei), el valor del principio de oralidad reside en los corolarios de la inmediación y concentración del juicio, las decisiones no se toman con base en escritos muertos, sino en la impresión recibida en la sala de audiencias (Ferrajoli, 1995, p. 620). Lo anterior no es nada distinto a lo sostenido por Parra Quijano en relación con el principio de inmediación donde el juez participa dentro del proceso en forma directa y personal en la producción de los medios de prueba que van a servir de sustento a su fallo (Parra Quijano, 2000 , p. 6). Este principio genera dos derivaciones muy significativas: «la exclusión de las declaraciones escritas como fundamento de la sentencia y la exigencia de que los testigos declaren en el juicio» (Parra, 2003, p. 24), es decir, la oralidad «es opuesta al régimen escriturario tradicional al que se le atribuye la mayoría de males atinentes a morosidad y consecuente impunidad de tan graves repercusiones para la paz social» (Bastidas y Ramírez, 2004, p.519).

Es claro que en el proceso penal y, específicamente, en el juicio oral el juez media y los testigos van en persona a él, ${ }^{2}$ y se puede interrogar y contrainterrogar a los mismos, Baytelman y Duce al respecto sostienen que:
La primera cuestión que es necesario despejar, aun cuando sea un tanto obvia en la lógica de un sistema acusatorio, es que la regla general del sistema solo considera como testigo a la persona que comparece al juicio a prestar declaración en la audiencia, sometiéndose a las reglas de examen y contraexamen. Su declaración personal no puede ser sustituida o remplazada por la lectura de actas anteriores en las que consten versiones previas de la misma. En este esquema, un testigo o la prueba testimonial jamás podrá ser la lectura de un acta o protocolo en el cual consta una declaración prestada en forma previa ante algún órgano del sistema (fiscalía o tribunal, por ejemplo). Solo es testigo y puede ser valorada como prueba testimonial la declaración prestada en juicio por la persona que comparece al tribunal bajo el formato de presentación de prueba testimonial (examen directo y contraexamen) (2005, p. 107).

Porque si no fuera así, de otro modo las decisiones serían contrarias a derecho, ya que, como lo afirma Bedoya, citando un aparte de una decisión de la Corte Europea de Derechos Humanos:

Cuando una condena está basada únicamente o en grado decisivo sobre disposiciones que han sido hechas por una persona que el acusado no ha tenido oportunidad de examinar o hacer examinar, sea durante la etapa de investigación o en el juicio, los derechos de la defensa están restringidos (2013, p. 40).

En el marco de esta comprensión garantista del proceso penal, teniendo en cuenta que la prueba testimonial es la prueba más recurrente e importante en los procesos, y si se quiere el principal medio para fallar, es donde cobra especial be-

1 Artículo $9^{\circ}$ del Código de Procedimiento Penal. Oralidad. La actuación procesal será oral y en su realización se utilizarán los medios técnicos disponibles que permitan imprimirle mayor agilidad y fidelidad, sin perjuicio de conservar registro de lo acontecido. A estos efectos se dejará constancia de la actuación.

2 Se exceptúa lo establecido en los artículos 284 y 437 del código de procedimiento penal. 
neficio y utilidad el estar al corriente sobre cómo interrogar y contrainterrogar a los testigos, indistintamente que sean de cargo o de descargo, como quiera que un buen litigante es quien sabe al dedillo y domina lo que se conoce como estrategias técnicas de litigación penal oral, pues de su apropiado y correcto uso depende mucho lo decidido en los estrados judiciales.

En nuestro país las instituciones encargadas de capacitar y formar a los operadores (principalmente fiscales y defensores públicos) han sido muy diligentes en la materia, porque saben la gran responsabilidad y compromiso que se tiene a cargo dentro de los recintos donde se llevan los juicios orales, llegando incluso a tener convenios con entidades internacionales como el Departamento de Justicia de los Estados Unidos de América y así sacar a la luz académica y profesional cantidades de manuales y módulos de consulta, los cuales interrelacionan tanto lo teórico como lo práctico. Es así como asumimos que antes de hacer uso de uno de ellos, es necesario en primer momento tener supremamente claro qué es la prueba penal y al dicho de Pedro Pablo Vargas y Taylor Londoño:

Son todas las razones, instrumentos, escritos, experticias, declaraciones, confesiones, etc., que, siendo medios de convicción o material de referencia, evidencias físicas, etc., llegan legalmente a la audiencia pública de juzgamiento (juicio oral), permitiendo al correspondiente juez adquirir la certeza respecto de la existencia del hecho imputado, de la responsabilidad o de la inocencia de los partícipes, de la personalidad de estos, de los motivos determinantes, de las circunstancias, de los daños materiales y morales ocasionados, de la cuantía de estos, etc. $(2005$, p. 3$)$.
De esta manifestación se desprende que la prueba testimonial no es la única prueba penal, por ello en igual sentido es de notable trascendencia definirla, y es: «la exposición o relato que un tercero hace ante el juez sobre los hechos o circunstancias relacionadas directa o indirectamente con el delito que se investiga» (Martínez Rave, 1999, p. 408).

Ahora sí es oportuno hacer uso de uno de esos módulos de consulta, y tenemos:

Que el interrogatorio es la manera como la prueba testimonial se presenta y practica en presencia del juez. Cada sujeto procesal pretende probar su teoría del caso a través de sus testigos, y esto se hace a través del interrogatorio. De ahí que un interrogatorio debidamente planeado y practicado conduce a la persuasión. La planeación del interrogatorio permite determinar cuáles son los hechos o las opiniones (peritos) relevantes de la teoría del caso que el testigo probará con su dicho, qué secuencia deberá seguir para explicarlos claramente, y qué temas y detalles son de importancia para la consistencia de su declaración. (...) La función del interrogatorio es presentar el testimonio de una manera efectiva, lógica y persuasiva. El interrogatorio es el arte de obtener información pertinente, clara, precisa y sencilla (2009, p. 141).

Desde la dinámica triangular que ofrece el proceso penal, esto es, dos partes iguales (fiscal y defensa) y un tercero supra parte (juez), ${ }^{3}$ no podemos dudar en momento alguno que el interrogatorio es un instrumento de un valor incalculable para alcanzar los objetivos propuestos por cada una de las partes, como para el mismo tercero imparcial, ya que a su cargo está decidir el derecho; es decir, el interrogatorio es una virtud y habilidad en la cual hay que

No significa que en nuestro sistema sean los únicos que están en juicio, en Colombia intervienen tanto víctimas como Ministerio Público. 
contar una historia de la forma más benéfica y favorecedora para los fines propuestos en el debate oral, por ello como lo sostienen Cadena Lozano y Herrera Calderón:

El interrogatorio es el arte de cuestionar y examinar a una fuente con el fin de obtener la máxima cantidad de información utilizable (usable), en el menor tiempo posible.

En otras palabras, el arte de interrogar es un proceso individual que depende de la personalidad del que interroga y de cómo logra comunicarse. Solo con el interrogatorio es como el juez puede disipar dudas y esclarecer puntos oscuros, y llegar así a una decisión razonada y justa, sin la cual es imposible pronunciar una condena que no sea arbitraria (2008, p. 83 ).

Es pertinente, entonces, caracterizarse y sobresalir por ser un litigante competente, ser un buscador sincero de la verdad y tener un estilo propio y definido. Ser auténtico y disciplinado a la hora de ejercer ese conjunto de preceptos y reglas necesarios para hacer bien ese acto de dirigir una serie de preguntas hacia una persona, quien deberá responder a las mismas desencadenando una dinámica de preguntas y respuestas, cuyo fin será el averiguamiento de la verdad real sobre los hechos investigados. No se nos puede quedar en el cajón del olvido que estamos en un sistema:

Netamente oral y conformado por audiencias públicas, donde ya no solo es el manejo de la normatividad procesal y de la prueba, sino que además es una necesidad básica el saber hablar, la oratoria se convierte en un todo, en la imagen, en la credibilidad, en un método de explicación, demostración y persuasión y en la única herra- mienta para obtener un fallo propio a nuestros intereses (Gómez Betancur, 2009, p. 24).

El abogado deberá reflexionar que el tiempo, energía y esfuerzo dedicado a la gestación y elaboración de un interrogatorio, como de su preparación particular y propia, es uno de sus quehaceres ineludibles e inexcusables en cada uno de sus casos si quiere salir avante de los mismos, en razón a que si el interrogador posee atributos y destrezas ${ }^{4}$ será mucho más sencillo el obtener una cooperación de sus fuentes testimoniales. Ahora bien, ¿por qué debe haber una preparación? La respuesta es muy sencilla y no es otra que los testigos generalmente son personas del común, los cuales no tienen como actividad diaria acudir a audiencias públicas; ellos deben ser preparados por quien les cita a declarar, deben ser familiarizados y amoldados con los procedimientos, con el ambiente físico de la sala de disputa, con cuáles temas se interrogarán y cuál podría ser un posible contrainterrogatorio efectuado por la contraparte, etc., esto hará mucho más fluida y eficaz su intervención. En este aspecto es muy importante no entender en una forma negativa la preparación de los testigos, queriendo con la misma cambiar, ocultar o desfigurar lo que el testigo tiene que narrar, es decir, tal diligencia no se destina a que falte a la verdad, sino, por el contrario, a resaltar la veracidad y la efectividad de su testimonio. Para el fiscal o el defensor que presenta su testigo, su habilidad en el interrogatorio es obtener la información de este, que el juez comprenda lo dicho por ese testigo y se persuada de ese dicho.

Muy claramente el texto Sistemas procesales y oralidad: teoría y práctica nos refuerza lo afirmado, indicándonos cómo debemos guiar al

\footnotetext{
Entre otras: motivación, tacto, paciencia, credibilidad, objetividad, autocontrol, perseverancia, habilidad para hablar, conocimiento integral, etc., (ver Cadena Lozano y Herrera Calderón, 2008, p. 86-89).
} 
testigo para que relate una historia ordenada sin que haya posibilidad de que omita información fundamental y resalta que el testigo es quien conoce los hechos y es la fuente primaria de la información, aseverando que los abogados experimentados reconocen que la mayoría de los casos se ganan por la fortaleza de su presentación y no por la debilidad de las otras partes procesales. El interrogatorio permite que el testigo sea el centro de atención. Después de todo, el testigo será creíble y recordado por la manera y el contenido de su testimonio, no porque las preguntas que se le formularon hayan sido brillantes (Reyes Medina, 2003, pp.137-138).

Sin embargo, nos aislaremos un poco de este último concepto de Reyes Medina. Las preguntas dentro del interrogatorio sí tienen señalada y valiosa importancia, y hay que considerar el tipo y la forma de formular las preguntas cuando viene la libre expresión del testigo. Primero, porque hay que evitar interrogatorios apresurados en los cuales el fallador no va a poder entender ni tener claridad sobre lo depuesto, y también porque los interrogatorios hay que hacerlos en un lenguaje no muy técnico, además, no podemos dejar de lado que es una actividad reglada; ello con el objeto de que se beneficie la verdad y la justicia, dado que es necesario que el testigo conteste con claridad, explicando todo lo que conoce al respecto y el motivo de ese conocimiento.

El artículo $392^{5}$ del Código de Procedimiento Penal preceptúa que el interrogatorio se hace observando unas instrucciones, lo cual nos confirma que la forma como se interroga sí es de capital importancia y los interrogantes se deben exponer buscando obtener un testimonio exacto. Otro de los módulos de estudio para operadores jurídicos señala, acerca del interrogatorio:

Debe realizarse con preguntas abiertas: qué, cuándo, cómo, dónde, describa, explique, etc. Su finalidad principal, es la de obtener información, que permita al juez, entender claramente la forma en que sucedieron los hechos. El interrogador debe conducir, y guiar al testigo a través de las preguntas para mantener un orden cronológico y mejor comprensión del asunto (Villegas Arango, 2008, p. 44).

Lo previamente establecido nos refuerza la postura que sí es pertinente hacer las preguntas de determinada manera. El comentarista Mario Arboleda Vallejo, citando a De Sanctis, manifiesta que «dentro de las preguntas afirmativas, negativas y disyuntivas solo esta última evita errores» (2013, p. 466). Las disyuntivas pueden ser parciales, ellas limitan al testigo evitando cualquier otra posibilidad de respuesta, por ejemplo: ¿era la casa de madera o cemento?, cuando podría ser de cualquier otro material, y pueden ser completas las cuales colocan en alternativa dos hechos, uno de los cuales es verdadero, por ejemplo: ¿es la pared de ladrillo o no?; esta clase de preguntas son muy seguras porque el testigo solo tiene dos alternativas para elegir: sí o no.

Peña González en su texto Técnicas de litigación oral nos manifiesta que para preparar

\footnotetext{
Reglas sobre el interrogatorio. Artículo 392. El interrogatorio se hará observando las siguientes instrucciones: a) Toda pregunta versará sobre hechos específicos. b) El juez prohibirá toda pregunta sugestiva, capciosa o confusa. c) El juez prohibirá toda pregunta que tienda a ofender al testigo. d) El juez podrá autorizar al testigo para consultar documentos necesarios que ayuden a su memoria. En este caso, durante el interrogatorio, se permitirá a las demás partes el examen de los mismos. e) El juez excluirá toda pregunta que no sea pertinente. El juez intervendrá con el fin de que el interrogatorio sea leal y que las respuestas sean claras y precisas.
} 
un interrogatorio lo más convincente posible debemos conocer las diferentes clases de preguntas:

\section{PREGUNTAS DESTINADAS A APORTAR INFORMACIÓN}

Preguntas narrativas

Son aquellas que permiten al testigo describir los hechos en sus propias palabras, provocando una respuesta vívida y hasta emocional.

Tienen la ventaja de aumentar la credibilidad del testigo porque demuestran su espontaneidad. El interrogador debe evitar, cuando utiliza esta clase de preguntas, formularlas de manera sugestiva, pues si lo hace será objetada.

Ejemplo:

¿Qué vio usted en la escena?

Las desventajas son las siguientes:

La respuesta puede llegar a parecer memorizada, especialmente cuando el testigo proporciona demasiados detalles.

El testigo puede aprovechar la pregunta para denigrar de otras personas.

El testigo puede desviarse del tema.

Preguntas abiertas

Son esencialmente preguntas narrativas, tienen como finalidad invitar al testigo a formular sus respuestas con sus propias palabras.

Ejemplo:

¿Cómo era el lugar?

¿Qué dijo Pedro cuando fue herido?

Preguntas cerradas

Son aquellas que se responden en forma corta, concreta y específica.

Ejemplo:

¿Qué marca es su automóvil?

Preguntas muy cerradas

Son aquellas que hacen que el testigo responda con un sí o un no, no sugiriendo la respuesta.

Ejemplo:

¿Usted trabaja?

\section{PREGUNTAS DESTINADAS A GENERAR CONFIANZA} EN EL TESTIGO

a) Preguntas introductorias y de transición Son aquellas que permiten a los testigos y al juez situarse en el contexto en el cual se va a desarrollar el examen directo.

Ejemplo:

Sr. Pérez, ahora voy a preguntarle acerca de sus relaciones con el acusado, específicamente de su relación profesional.

Las preguntas de transición se utilizan para determinar cuándo termina la narración de un hecho y continúa con otro. De igual manera, son utilizadas para reconducir al testigo o para que precise algún punto que está declarando, buscando respuestas específicas.

Ejemplo:

Establecido lo anterior, Sr. Pérez, ahora quisiera que nos centremos en qué sucedió durante la reunión del 7 de abril. (...) (2014, p.238 y ss.).

Lo plasmado hasta aquí no puede significar nada distinto a lo ya sostenido, o sea, que la forma y modo de las preguntas en un interrogatorio sí son importantes, las indagaciones han de ser trasparentes y limpias, porque el testigo debe responder de forma espontánea, basado en experiencias personales, porque quien hace el interrogatorio no puede arrastrar ni influir en la respuesta del testigo, y del mismo modo no se puede poner a hablar a los testigos de todos los hechos, sino únicamente de aquellos que le constan directamente y resultan relevantes o importantes para probar la teoría expuesta por la parte.

Hay que tener claro que las preguntas dirigidas deben tener un propósito. Hay que evitar hacer interrogantes en forma descuidada, sin un plan definido, no se trata de lanzar preguntas solo para oír lo que pueda responder la persona, es mejor abstenerse de formular preguntas que enunciarlas torpemente. Para hacer unos interrogatorios con seguridad y efectividad. Pabón 
Parra nos ilustra de qué formas se deben abordar los mismos, entre ellas se destacan:

Interrogatorio en secuencia

La formulación de preguntas en secuencia estricta, lógica, ontológica, cronológica o cualquier otro orden que se le quiera dar, es la primera opción que se presenta en la mente del interrogador, pues lo previene contra las «omisiones imperdonables», que no se le queden asuntos por tratar, al mismo tiempo le asegura contra la mala formulación de preguntas, simplemente debe limitarse a ir "chuleando" las diversas cuestiones que ha preparado, hasta evacuar la totalidad del temario en consonancia con los objetivos que se ha trazado (2005, p. 414).

Esta es una técnica muy utilizada según el autor para interrogadores inexpertos, o cuando la complejidad del tema, o la deficiente información de que dispone haga que aflore la inseguridad sobre los resultados de la diligencia, también afirma que este método hace muy predecible el curso del interrogatorio y el factor sorpresa no está presente. Otras técnicas son:

Interrogatorios escalonados, progresivos y amplios

Esta técnica se ofrece como variante o complemento de la anterior y puede ofrecer similares dificultades; con ella el interrogatorio se presenta de manera escalonada, partiendo de lo genérico para llegar a lo específico, siempre sobre los aspectos principales de la controversia y los hechos objeto de juicio que podría conocer el testigo.

Interrogatorio en «zigzag».

El interrogador debe saber que el orden de las preguntas no es fijo ni preestablecido, pues la Ley no suele imponer límites expresos en este campo, salvo los deberes de lealtad, art. 392 inc. 2. El interrogador está totalmente facultado para introducir variantes y «saltar» a su arbitrio por los diversos temas que se deben abordar; de esta manera pue- de marcar, de acuerdo con su criterio, el curso del interrogatorio (Pabón Parra, 2005, p. 416).

Este interrogatorio, según el autor, se caracteriza por que el orden y la conexión lógica entre las diferentes preguntas no se advierte a primera vista, aquí se formulan una o varias preguntas sobre un tema, una vez emitidas las respuestas se pasa de inmediato a otro punto sobre el cual formula también una o dos preguntas, luego aborda un tercer tema, y después retoma el primero o el segundo formulando preguntas aun no expuestas.

Ahora bien, en muchas ocasiones hay testigos que no están dispuestos a contar toda la verdad, debido a que auxilian algún interés personal en relación con la parte de cuyo lado han sido llamados a testificar, o porque simplemente no quieren colaborar con el desarrollo normal de las diligencias, es allí donde igualmente deriva la importancia de la categoría de las preguntas con que se debe abordar el interrogatorio. Razón tenía Mas Forns al recomendar que:

Debe estar prevenido el interrogador ante las agudas, rápidas contestaciones de algunos deponentes de viva imaginación y pronta percepción de la intención o finalidad con que se les interroga, a fin de no perder el control en la dirección del interrogatorio ni dejarse arrastrar hacia los planos secundarios de la materia objeto del debate, llevado por la sutileza e interés de aquél para desvirtuar o eludir las preguntas básicas del interrogatorio (1951, p. 24).

Para estos efectos Pabón Parra trae el interrogatorio de testigos cuya imparcialidad puede estar afectada y recomienda que ante los testigos que se advierte parcialidad, el interrogador deberá cuidarse, en lo posible, de no dejar vislumbrar los objetivos que persigue con la formulación de cada pregunta, con ello puede alcanzar algún nivel de objetividad en la res- 
puesta. La introducción en la formulación de elementos distractores puede hacer que en un primer momento el testigo no advierta su relación con el tema, le puede llegar a parecer innecesaria o inocua y procederá a responderla sin prevenciones, lo cual significará un gran acercamiento a la fidelidad de la exposición (2005, p. 418).

Para dar cierre al examen directo, es acertado enunciar cuáles preguntas no se pueden realizar dentro del interrogatorio y son las que la doctrina ha clasificado como tipo de preguntas objetables. Los chilenos Baytelman y Duce dicen que son básicamente cuatro:

a) No se pueden formular preguntas sugestivas.

b) No se admiten preguntas capciosas ni en el examen directo ni en el contraexamen.

c) No se admiten preguntas destinadas a coaccionar ilegítimamente al testigo.

d) No se admiten preguntas formuladas en términos poco claros al testigo (p. 220).

Estas prohibiciones son perfectamente aplicables a nuestra legislación. Con respecto a la primera de ellas ya hemos sido lo suficiente claros en que no es apropiado hacerlas porque sería el interrogador quien incorporaría la información al juicio y no el testigo. Las segundas son las conocidas como engañosas, inducen al error al declarante y por obvias razones no se deben permitir. Las terceras dejan claro que sobre el testigo no se pueden ejercer presiones ilegítimas que comprometan su forma de dar las respuestas, y, por último, las poco claras son todas aquellas ambiguas, confusas, imprecisas etc., y es evidente que van en contra del sentido y fin del derecho. Cadena Lozano y Herrera Calderón extienden las clases de preguntas vedadas destacándose las:

Argumentativas y son aquellas que contienen una inferencia o deducción para que el testi- go rechace o confirme, lo que se pretende con la pregunta. (...) preguntas compuestas las que involucran varios interrogantes en ella, que de acuerdo con la forma del interrogatorio deben formularse de manera independiente; preguntas conclusivas y son las que el declarante acepta las conclusiones que propone quien interroga; preguntas de opinión los testigos no deben dar opiniones o juicios, salvo que sea un perito o testigo técnico; preguntas especulativas y son en las que el interrogador crea una hipótesis para que el testigo la confirme o niegue, etc. (p. 105 y ss.).

Tomaremos a partir de las siguientes líneas el contrainterrogatorio, el cual ha sido entendido como:

Un instrumento de confrontación mediante el cual una de los intervinientes pretende demostrar al juez que la teoría del caso de la contraparte carece de veracidad, permite apreciar el verdadero alcance y contenido del testimonio y limitar la declaración adversa a sus justas proporciones, 0 cuando menos mostrarle al juzgador que las cosas no exactamente ocurrieron como el testigo las describió, bien porque algo sucedió en menor dimensión (confrontación a las exigencias del testigo), o bien porque se omitió algo que era relevante para valorar el testimonio (confrontación dirigida a omisiones del testigo) (Decastro González, 2005, p. 5).

Los distintos autores no discrepan en afirmar que los abogados no saben cómo actuar y dirigir un contrainterrogatorio, que no tienen una idea clara de lo que hay que hacer y cómo hacerlo. Víctor Orielson León Parada manifiesta que:

Si no se calcula bien la pregunta, puede correr el riesgo de tener serias dificultades, sea para la causa que se defiende, sea por la censura del juez fallador, sea porque el testigo se aprovechará de la incapacidad suya, cuando le formule la pregunta. No olvide que la pregunta a reformular en la etapa de contrainterrogatorio, debe ser 
tomada y estructurada de las preguntas contestadas en el interrogatorio directo o inicial. Caso contrario, será objetada en forma inmediata, sea por la contraparte, por el mismo testigo que se niega a responderla o por el juez de la causa (2007, p. 214).

El punto o zona que se pretende alcanzar $u$ ocupar con el contrainterrogatorio es:

Hacer ineficaz o menos eficaz el interrogatorio. Poner en duda la historia del oponente, hacerla menos creíble y en lo posible ilógica, de manera que lo que llegó al juez a través del interrogatorio, no sea absolutamente perfecto o sin contradicción o hacer notar los contenidos ilógicos. El contrainterrogatorio se desarrolla a través de preguntas afirmativas, aclaratorias, confirmatorias, sugestivas, repetidas y cerradas. También se prohíben las preguntas capciosas.

Si el testigo es eficaz cuando es claro, lógico, creíble, indubitable, su dicho no riñe con la lógica o las reglas de la experiencia; por eso el sentido del contrainterrogatorio es llevar al testigo a dudar, a contradecirse, a que sus pronunciamientos sean inseguros o en contradicción con las reglas de la experiencia y la lógica.

En desarrollo de lo anterior, se debe evitar repetir el interrogatorio; debe existir un conocimiento profundo y detallado de cada episodio con el objetivo de que el testigo muestre sus dudas e inconsistencias.

No se debe contrainterrogar sin necesidad. Uno de los mejores contrainterrogatorios puede ser el que no se hace. Se debe tener claro que se contrainterroga cuando se perjudicó la teoría del caso, de no ser así, no tiene sentido hacerlo.

Se debe conocer con anticipación la respuesta del contrainterrogatorio, de lo contrario no se debe hacer (Zuleta Cano y Noreña Castrillón, 2012, p. 43-44).
Es decir, hay que poner a prueba la verdad, hay que despojar y tomar del testigo información favorable a nuestros intereses y desacreditar al testigo en lo dicho en su testimonio directo. El propósito no puede ser otro que el examinar la autenticidad y credibilidad del testimonio y de la persona interrogada; en otras palabras, es quebrar la fuerza del testimonio adverso y reforzar el propio.

En palabras de Pabón Parra lo que se pregunta en el contraexamen tiene tres fines básicos:

a) Abolir o reducir la credibilidad del testigo por sus condiciones subjetivas, vale decir, en dirección a su idoneidad. b) Desvirtuar las afirmaciones o negaciones realizadas en la declaración directa, para lo cual pueden presentarse diversidad de motivos: porque ha mentido, porque ha exagerado su conocimiento -declaración increíble-, porque ha entrado en contradicción o inverosimilitud, porque ha presentado una versión falsa por omisión o error, entre otras. c) Obtener datos, citas o referencias que el testigo pudo haber silenciado y que de ser reveladas pueden generar conclusiones diferentes o hacer menos creíble el contenido del testimonio directo. (Pabón Parra, p. 45).

Empero para poder alcanzarlos hay que tomar en cuenta y saber que:

Cada testigo es una nueva experiencia y cada proceso judicial un universo, por lo que cada contrainterrogatorio será único e irrepetible. La adhesión a una determinada regla o línea de preguntas puede conducir al éxito de un juicio y al rotundo fracaso en otro. Eso es lo que hace del contrainterrogatorio un verdadero arte sujeto a un constante trabajo. Ningún abogado litigante llegará jamás a un estado en el que, para contrainterrogar a un testigo adverso, no necesite prepararse ni comenzarlo todo de cero, repasando a cada momento la aplicación de las reglas del contrainterrogatorio. 
PRIMERA REGLA: NO SOLICITE EXPLICACIONES (...). SEGUNDA REGLA: NO HAGA UNA PREGUNTA SI NO CONOCE LA PROBABLE RESPUESTA (...).

TERCERA REGLA: NO REPITA EL INTERROGATORIO DIRECTO (...).

CUARTA REGLA: NO DISCUTA CON EL TESTIGO (...). QUINTA REGLA: CONCÉNTRESE EN EL TESTIGO Y SUS RESPUESTAS (...).

SEXTA REgLA: DESARROLLE UN SENTIDO ESTRATÉGICO Y DE OPORTUNIDAD (...).

SÉPTIMA REGLA: SEA BREVE (...).

OCTAVA REGLA: MANTENGA EL RITMO (...) (Decastro González, p. 474).

Es acertado darle cierre al presente con la siguiente aseveración:

Prueba y verdad se hayan correlacionadas a tal extremo que podría decirse que no hay verdad sin prueba, en cuanto la prueba es la piedra de toque, el medio de aquilatar, de admitir la evidencia incuestionable de la verdad, de verificar (verum) la verdad encontrada, de cerciorarnos (certus) de su exactitud, de su certeza legítima. Toda verdad debe resistir a la prueba de la duda y salir triunfante de ella, por medio de la prueba, de la cual podríamos decir que es hija de la duda y madre de la verdad (Dellepiane; citado por Sierra Ospina, 2008, p. 34-35).

\section{Conclusiones}

Indiscutiblemente, la nueva sistemática penal se deberá caracterizar y definir por la capacidad y aptitud de sus partes e intervinientes en el manejo de las herramientas otorgadas por la misma, todo en razón y en procura de extraer siempre la verdad de lo debatido en juicio.

La litigación oral, la técnica y las habilidades procesales deben sobresalir en los buenos litigantes porque en sus favores y asistencias están en juego derechos de excelsa y magna jerarquía, como la libertad de una persona o el derecho a conocer la verdad de una víctima. Es por ello que ese oficio o arte de interrogar y contrainterrogar, se logra, no leyendo, sino practicando.

\section{Referencias}

- Avella Franco, P. (2007). Estructura del Proceso Penal Acusatorio. Bogotá: Fiscalía General de la Nación.

- Bastidas de Ramírez, R. y Ramírez Bastidas, Y. (2004). Principalística Procesal Penal. Bogotá: Doctrina y Ley.

- Baytelman A., A. y Duce J., M. (2005). Litigación penal juicio oral y prueba. México: Fondo de Cultura Económica.

- Bedoya Sierra, L. (2013). Prueba de referencia y otros usos de declaraciones anteriores al juicio oral. Medellín: Comlibros.

- Cadena Lozano, R. y Herrera Calderón, J. (2008). Técnicas de interrogatorio y Contrainterrogatorio en el Sistema Acusatorio. Bogotá: Ediciones Jurídicas Andrés Morales.

- Decastro González, A. (2005). El Contrainterrogatorio. Medellín: Comlibros.

- Ferrajoli, I. (1995). Derecho y Razón. Madrid: Trotta.

- Gómez Betancur, W. (2009). El orador no nace, se hace. Medellín: Librería jurídica Sánchez. 
- González Obregón, D. (2014). Manual Práctico del Juicio Oral. México: Tirant lo Blanch.

- Jaramillo Díaz, J. (2008). Reflexiones sobre el Sistema Acusatorio. Medellín: Librería Jurídica Sánchez.

- León Parada, V. (2007). El interrogatorio penal bajo una pragmática oral. Bogotá: Ecoe Ediciones.

- Martínez Rave, G. (1999). Procedimiento Penal Colombiano. Bogotá: Temis.

- Mas Forns, R. (1951). Aspectos del interrogatorio judicial en lo criminal. Madrid: Instituto Editorial Reus.

- Pabón Parra, P. (2005). Oralidad testimonio interrogatorios y contrainterrogatorios en el proceso penal acusatorio. Medellín: Librería Jurídica Sánchez.

- Parra Quijano, J. (2000). Manual de Derecho Probatorio. Bogotá: Librería del Profesional.
Peña González, O. (2014). Técnicas de litigación oral teoría y práctica. Medellín: Librería Jurídica Sánchez Ltda.

Reyes Medina, C. (2003). Sistemas procesales y oralidad: teoría y práctica. Bogotá: Ediciones Nueva Jurídica.

Reyes Medina, C. (2009). Técnicas del proceso oral manual general para operadores jurídico. Bogotá: Ediciones Nueva Jurídica.

- Sierra Ospina, G. (2008). El sistema acusatorio y la prueba. Medellín: Editorial Universidad de Medellín.

- Vargas, P. y Londoño Herrera, T. (2005). Las pruebas en el sistema penal acusatorio colombiano. Bogotá: Doctrina y Ley.

- Villegas Arango, A. (2008). El juicio oral en el proceso penal acusatorio. Bogotá: Fiscalía General de la Nación.

Zuleta Cano, J. y Noreña Castrillón, L. (2012). Otras experiencias forenses. Medellín: Librería Jurídica Sánchez. 